\title{
On the Impact of Japanese Social Culture on Language from Japanese Ellipsis Phenomenon
}

\author{
Liu Shuangxi \\ Foreign Language Department of Tangshan College
}

\begin{abstract}
Ellipsis is commonly seen in daily and oral communication, especially in Japanese. Japanese grammar scholar Mr. Matsuo Sajiro summarizes ellipsis as one of the three major features of Japanese. This paper makes a summary on ellipsis, and further makes a research of the root reasons in social culture for ellipsis.
\end{abstract}

KEYWORD: ellipsis phenomenon; culture background; Sino-Japan communication

Any language is shaped by its particular social culture context. The ellipsis phenomenon also reflects features of Japanese culture. If we can not recognise Japanese ellipsis from this aspect, it will be an obstacle for us to the study of Japanese culture, the communication with Japanese, the better understanding of cross-culture communication. First, let's make a summary of the Japanese ellipsis.

\section{THE ELLIPSIS OF SUBJECT}

(1) It is getting warmer, isn't it?

(2) $\mathrm{Tt}$ is raining.

(3) Maybe there is nothing to your liking, plaese have a try.

In the subject-omitted sentences, it is a most common phenomenon to omit pronouns which act as subjects. In daily Japanese conversation, pronouns like "watashi" or "anata" are seldom used.

There are some other types of pronoun ellipsis.

\subsection{The ellipsis can be made if there are some verbs with directivity}

In Japanese, there is a kind of words with a function of speaker-directing, which express the speaker's state of mind. When this kind of verbs act as predicate, usually we can infer who the speaker is, so the pronouns as subject can be omitted. When it comes to verbs, "omou" is a good example.

(4) Every time the past hit me, I would feel sad.

(5) I always worry about the children's future.

Be similar to "omou", there are many other verbs with this fuction, such as "kangaeru" "kannjiru" "shinjiru" "komaru" "mozomu" "kogasuru" "kanjigasuru" "komochigasuru" and so on. The subject of these verbs is "watashi(I)", so when they appear at the end of a sentence, the subject at the beginning of the sentence must be omitted.

\subsection{Ellipsis can be made if there are some subjective adjectives.}

Japanese adjective can be divided into two groups, one is objectives which express objective nature and state, the other is subjectives which express subjective feelings and affections. When subjective adjectives act as predicate with original form, the feelings and affections all point to the speaker, i.e. the first person pronoun. For instance:

(6) I am so glad to have the chance to meet you.

(7) I felt so happy today.

There are some adjectives with the same fuction, such as "kanashii" "kowai" "hazukashii" "urayamashii" "itai" "kuyashii" "kimochiwarui" and so on, and adjectival nouns like "zannenda".

\subsection{Ellipsis can be made if there are some auxiliary words express wills, willing, wishes and requiremen-ts.}

(8) I don't want to go to school for the headache.

(9) This, for you.

\section{THE ELLIPSIS OF PREDICATE}

Predicates play an important role in Japanese. Predicates at the end of a sentence can decide whether it is positive or negative, now or past, and whether it expresses doubt or speculation, order or 
prohibition. Though predicates are very important in Japanese, there are many sentences in which predicates are omitted. We can take a look at predicate ellipsis in the following aspects.

\section{1 "Unagi"}

(10) "bokuga unagida."

The meaning of this sentence pattern "...wa...da." Is "A is B". But according to this logic, it is wrong to take the sentence meaning for "I am an eel". This is also a kind of ellipsis. The actual meaning it conveys is "bakuwa unaginisuru.(I want to order eels)" or "bokuwa unagiwo tabeyoutoomotteiru.(I want to eat eels)". This sort of sentences must appear at an asking-answering context. Take the above for example, it is on the condition of being asked by "kimiwa naninisuruka". This kind of predicate ellipsis is called "unagibun".

(11) Who ordered the black tea?

It is me.

(12) What is your major in college?

I am English.

Japanese utterances put a highlight on important new information and play down on the inferior old information, thus omitting the unimportant old information. When answering the sentence as above, the emphases should be paid on the new information people care about, and make no repetition about the information appears in the noted sentence.

\subsection{Predicate ellipsis caused by auxiliary words.}

Japanese belongs to agglutinative language, while auxiliary words are one of the major features. According to the classification rules of Japanese part of speech, auxiliary words are a kind of functional words with no morphologic change and no actual meaning. It must follow words, phrases, and sentences, and cannot be used alone as a sentence composition, with the function of expressing the relation between compositions before and after it, or adding some meaning or language sense. Therefore, in some specific situations, we can infer the meaning of a sentence as long as noticing the auxiliary words. Consequently, the phenomena like omitting other compositions according to auxiliary words are rather common.

A. case-auxiliary

Case-auxiliary indicates the word order. When the property of the preceding words is quite clear, the subsequent words can be easily omitted. For instance:

(13) Where are you going?

Go around.

(14) Please come here.

In Japanese proverbs, case-auxiliary plays the same ellipsis role. e.g.

B. Accessory Word
The accessory word is used to connect words or phrases and sentences, which serves as a connecting link between the preceding and the following. Its omission in a sentence is very obvious. For example:

(15) How about going to see a doctor?

(16)It is a small gift as a token of my appreciation( Please take it).

C. Hint of utterances

Hint of utterance lies in the front of the predicate or between it, strengthening the tone of doubt, ask, negation and stress. The predicates behind it are usually omitted.

(17) ( I didn't think) There were such a thing.

(18) I will be leaving now.

So will I.

\subsection{The omission of predicate caused by adverbs}

In Japanese daily conversations, there are a lot of examples using adverbs to form a sentence and omitting the predicate. For example:

(19) Are you busy this afternoon?

No, (I am not busy).

(20) It is said that Sir. Shan Tian got a divorce.

Not really?

There are still many such examples. For instance, (Are you hungry?) (Not at all). All these answers omit the predicates.

\section{THE ELLIPSIS IN THE DUTY-PERFORMING}

In Japanese, there are seven giving verbs. $\lceil$ yaru $\rfloor$

$\lceil$ ageru $\rfloor\lceil$ sashiageru $\rfloor\lceil$ morau $\rfloor\lceil$ itadaku $\rfloor$

$\lceil$ kureru $\rfloor\lceil$ kudasaru $\rfloor$.There don't appear personal pronouns in these sentences that use giving verbs. For example:

(21)I want you to give us some examples.

(22)My friend gave me a dictionary.

(23)I got a dictionary from my friend.

The example in the book of Mr. Kindaichi Spring Japanese Language is used in many grammatical teaching, namely:

If the sentence is translated into Chinese (The photo studio is good, so let's go there to take photos), the delicate relationship in original Japanese meaning can't be well expressed because we add the omitted personal pronoun.

\section{THE ELLIPSIS IN THE HONORIFIC}

It is a difficult part to use the honorific in Japanese for most of foreign learners. But in term of the composition of the sentence structure, there seldom appear the personal pronouns when using the honorifics. Instead, we need to suppose the relevant person through the honorific in the end of the 
sentence, which is the most difficult part for foreign learners. For example:

Start-bound complements $\lceil\mathrm{o}\rfloor \quad$ go $\rfloor$

(27)Can you spare some time for me?

(28)Is it convenient for you?

\section{THE SOCIAL CULTURAL ENVIRONMENT THAT CONSTITUTES ELLIPSIS}

Why there are so many ellipses in Japanese? The reason is the soil that generates the language — - the natural environment and the social environment.

\subsection{Congenital natural geographical environment and the cooperation mode of production formed the nature of the Japanese natural tacit cooperation.}

As we all know, Japan is a sea girt island. The Tsushima Strait separates Japan and the Asian continent about $160 \mathrm{~km}$, which is larger five times than the Dover Strait between the British and the European continent. Some Japanese scholars called the geographical environment as "natural geographical isolation." The seclusion orders published by the Tokugawa Shogunate isolated Japan from the outside except China, Korea and Netherland from 1663 to 1853 , nearly 200 years. Long-term isolation from the rest of the world has made the Japanese the unity nation character, namely the so-called homogeneity of the Japanese nation.

Japan is a nation that depends on the agriculture and fishery from the ancient time. Fishing on the sea requires the labors work closely; otherwise it is not only bad for fishing, may also brings disaster. At the same time, the Japanese eat rice, mainly produced in the mountainous regions taken up 70 percent of the nation territory area. Growing rice in the mountains requires the collective idea, or it will produce conflict between the farmers on higher topography and the farmers in low areas on using water. The mode of production made the Japanese develop the overall collaboration personality and character standing on the position of the others to consider problem. It needs not too much language when the Japanese communicate with each other because of the national homogeneity. Instead they can understand each other by using eye contact, facial expression and body language. And at the same time it also applies to the exchange of the ideas. Those who don't adapt to the form of communication will be regarded as $\lceil$ satsushiwaruihito $\rfloor$. It formed the nature of the Japanese tacit cooperation as time passes.

\subsection{Traditional culture makes Japanese have more affinity in mind}

Japanese traditional culture has appeared and developed in such natural environment and production mode that mentioned above, thus forming an outstanding character of less obvious local community subculture characteristics. Therefore, from the perspective of their traditional culture, there are number of self-explantory conventions in Japanese mind. As language being the main mode of cultural transmission, Japanese tend to use more brief expressions because of the traditional cultural background.

\subsection{Japanese prefer short sentences because of the popularization of versicle and haiku, etc}

In Gao Muwu's <日本文学の本質について>, he points out narrow as the main characteristics of Japanese literary, which is very reasonable. Taking versicle as example, it's famous for its "short" that is said to have no equal in this world, and the famous literature forms waka and versicle as well are renowned for short.

Represented by versicle, Japanese literature has stretched from Nara and Heian period up to now, enduring through hundreds of years. Brief but not destitute, deep-meaning along with its exquisite artistic conception, must be the most important reason for its long-lasting existence.

The traditional old saying "A voice worths invaluable, and a word worths priceless" has demonstrated their general concept of "Passages are precious for short, speak less for better understanding". We must admitted that it is Japanese traditional culture exerted a subtle influence on the formation of such universal atmosphere. Take a look at the following vivid example here:

Asahi Shimbun once published a interesting short story: One of the team members working at Japan Showa Station located in the south pole one day received a telegram form his wife in Japan, with only three Kana words "you" on it, and it won a great admiration among the team.

In this story, we non-Japanese people may only see a regular second personal pronoun out of the three Kana words, but to Japanese it expresses a wife's infinite warmth and love as well as wordless thoughts and care that can be called a love letter warm enough to melt the ice in the Antarctic.

\subsection{Information dissemination changes make Japanese more concise and comprehensive}

As Japan has entered the information-based society where image-text has become the main way of information dissemination, people acquire all sorts of information by their vision, for example by watching $T V$, reading newspapers or fax letters, or 
even by watching notice board on the streets. While "listen", as another media, has to relegate to second place.

It is well-known that many a languages in the world convey the connotation by sounds or expressions, and merely Japanese uses a mixture of both_-by sounds of Kana words and by expressions of the Chinese characters: Kana words are defined by Japanese as to listen, while Chinese as to look. Therefore, one sentence in Japanese may have different expressions through two ways of both vision and the sense of hearing, this is the unique feature of Japanese. For example, there is a massage on the radio: "Tomorrow prime minister Tomiichi will pay a official visit to China, however, it changes to a much more brief version of prime minister Tomiichi tomorrow visit China on newspaper or TV.

The widespread use of Chinese vocabulary has promoted the development of Japanese ellipsis and simplification. Not just to be seen in the category of news and media, the trend has already run its way into the daily life of Japanese family. Check the following example:

A grandma has tried to persuade her grandson not to wear long hair: over and over again without a success. One day, his father yelled at him: "and pinned a note saying (no long hair) up on the wall in his bedroom, as a result, the boy finally cut his hair the next day. In one hand, of course the father being strict to the son has successfully worked, but the other hand what's more important is the Chinese vocabulary's brief shocking effective that works on one's memory to be seen in this little family case.

All in all, including what mentioned above, Japanese prefer to simplify their words by cutting out the superfluous for different multi-level reasons. And as I have learned Japanese more and more, I've developed one personal point of view that the reasons for Japanese like their language to be brief at large are actually connected with their nature of ambiguity and sympathy for each other, namely the same strain of Yamato.

\section{CONCLUSION}

Ellipsis in Japanese reflects Japanese cultural innovation. If we failed to better understand Japanese ellipsis from this angle, there will be obstacles in the access to its culture, communication with Japanese and even other cross-cultural communication study. In fact, what makes Japanese shorter but clearer and arouse more our tender emotions is their thought patterns to arrange their words, the so-called 「発想」—_ always put yourself in your listener's position. While these quite distinct from Chinese. We tend to use straight talk to point out what we want or what we want not, and complete our words to make ourselves as clear as possible so as to show our honesty. Japanese want themselves to sound friendly using some amphibolous words and expressions to avoid sharp stimulus. And this is the key point that there are situations that we may have some misunderstanding about Japanese, and that is why we do not expect to have a comprehensive understanding of Japanese and their language without devoting ourselves to the similarities and differences based on analysis and comparison of the cultural background. But what should emphasized is that Chinese say everything they know without reserve and Japanese would always contain much but reveal little when they talk. There exists some differences in two languages, and smooth communication should be based on certain improvement in our language ability, which will help us understand Japanese culture thoroughly and ensure cultural exchange between Chinese and Japanese.

\section{REFERENCES}

[1] Ma Andong. Japanese conversation pragmatic analysis of ellipsis phenomenon, foreign language teaching, 2002(1); university (humanities and social science edition 2010(3);

[2] Sun Yanli. Subject of ellipsis phenomenon in Japanese, Journal of jilin normal, Journal of huaihai institute of technology (social science edition); 2011 (2);

[3] Liu Hongyan. The omission phenomenon in Japanese and its culture connotation

[4] Sheng Zuxin. Shallow of ellipsis phenomenon in Japanese, Japanese knowledge, 2003 (5). 